\title{
Acute Alcohol Consumption and Motivation to Reduce Drinking Among Injured Patients in a Swedish Emergency Department
}

\author{
Anna Trinks, MSc, \\ Department of Medical and Health Sciences, Linköping, Sweden \\ Karin Festin, PhD, \\ Department of Medical and Health Sciences, Linköping, Sweden \\ Preben Bendtsen, PhD, \\ Department of Medical and Health Sciences, Linköping, Sweden \\ Cheryl J. Cherpitel, DrPH, and \\ Alcohol Research Group, Berkeley, California \\ Per Nilsen, PhD \\ Department of Medical and Health Sciences, Linköping, Sweden
}

\begin{abstract}
Background-Injuries constitute a major public health problem. Millions of people are injured each year and acute drinking is a well-known risk factor for injuries. Research suggests that acknowledgment of alcohol as a factor in an injury enhances willingness to change drinking behavior, possibly because the patient becomes aware of the negative consequences of their drinking.
\end{abstract}

Study Objectives-To investigate the prevalence of acute alcohol consumption (drinking prior to the event) among injury patients and to examine the importance of factors potentially associated with motivation to reduce alcohol consumption among these patients.

Methods-All patients aged 18-69 years were requested to answer alcohol-related questions on a touch-screen computer.

Results-Fifteen percent of injured patients were categorized as acute drinkers and, of these, $64 \%$ reported that their injury was connected to alcohol. There were significant differences for all sociodemographic and drinking characteristics between acute drinkers and non-acute drinkers. Acute drinkers were categorized as risky drinkers to a much higher extent than non-acute drinkers. Acute drinkers had a considerably higher average weekly alcohol consumption and engaged far more frequently in heavy episodic drinking than non-acute drinkers. Acute drinkers were motivated to reduce their alcohol intake to a greater extent than non-acute drinkers; $51 \%$ were in the action, preparation, and contemplation stages, compared with $19 \%$ of the non-acute drinkers.

Correspondence related to content to: Anna Trinks, Department of Medical and Health Sciences, Hälsanshus, Plan 11, Linköping 58183, Sweden. anna.trinks@liu.se.

Declaration of interest: The authors report no conflicts of interest. The authors alone are responsible for the content and writing of the paper.

The authors report no conflicts of interest. The authors alone are responsible for the content and writing of the article.

Publisher's Disclaimer: This is a PDF file of an unedited manuscript that has been accepted for publication. As a service to our customers we are providing this early version of the manuscript. The manuscript will undergo copyediting, typesetting, and review of the resulting proof before it is published in its final citable form. Please note that during the production process errors may be discovered which could affect the content, and all legal disclaimers that apply to the journal pertain. 
Conclusion-Acute drinkers had considerably more detrimental alcohol consumption than nonacute drinkers and the acute drinkers were more motivated to reduce their drinking than the nonacute drinkers.

\section{Keywords}

alcohol consumption; acute drinking; motivation to change; injured patients; emergency department

\section{Introduction}

Injuries constitute a major public health problem. Millions of people are injured each year and alcohol consumption is a well-known risk factor for injuries (World Health Organization, 2007). For every death due to injury in Sweden, there are approximately 30 hospitalizations due to injury and an additional 200 injuries treated at emergency departments (ED) (MSB, 2010).

Injured patients in the United States who visit the ED have a higher weekly average consumption and engage in heavy episodic drinking (HED) more frequently than the general population in their region (Cherpitel, 1993, 1995, 1999; World Health Organization, 2007). In Sweden, three studies have been conducted on patients with non-fatal injuries associated with alcohol, with a wide range of average consumption (Nilsen, et al., 2007a; Nordqvist, et al.,2006; Romelsjö, et al., 1993). Similar results have been seen in other European countries (Allely, et al., 2006; Deutch et al., 2004; Kuendig, et al., 2009; Kuendig, et al., 2008; Vitale, et al., 2005; World Health Organization, 2007).

Research suggests that acknowledgement of alcohol as a factor in an injury enhances willingness to change drinking behavior, possibly because the patient becomes aware of the negative consequences of their drinking (Longabaugh et al., 1995; Nilsen, et al., 2007b). The physical or mental distress of the injury and the subsequent visit to the ED or hospitalization could lead to a decrease in drinking independent of any interventions (Bombardier, et al., 1997; Bombardier \& Rimmele, 1998). However, such an intervention effect appears to be only temporary if the underlying alcohol consumption is not addressed (Gentilello et al., 1999).

The present study addresses important knowledge gaps in alcohol and injury research. There is a paucity of research on the potential effects of an injury on motivation to reduce drinking.

Aim

The aim of the study was to investigate the prevalence of acute alcohol consumption (drinking prior to the event) among injury patients in a Swedish ED and their sociodemographic and drinking characteristics. The aim was also to examine the importance of factors associated with motivation to reduce alcohol consumption among these patients.

\section{Methods}

The study was carried out over a 1-year period at the ED facility of Motala County Hospital, between March 2007 and March 2008.

All patients aged 18-69 years registered at the ED triage room were given a card (in Swedish) by an emergency nurse with a request to answer some alcohol-related questions on a touch-screen computer located in the adjacent ED waiting room. Patients arriving by ambulance were excluded from the study, as they did not have access to the computer. 
Patients who received immediate care and patients who the emergency nurses considered to be too ill, injured, intoxicated or fragile to complete the computerized questionnaire were excluded. Participation was voluntary and the patient could exit the computer program at any point. Patients who completed the program received a printout (one page), containing personalized feedback on their drinking habits, as calculated by the computer from the patient's answers. The patient picked up the printout by the computer and it was not available to any of the staff. No further person-to-person feedback was provided.

The flow of patients is described in Figure 1. A total of 9386 patients aged 18-69 years were admitted to the ED during the study period. Of these, 1978 patients arrived by ambulance and did not present to the triage room, and thus were excluded from the study. A further 544 patients received immediate care and were registered at the triage room afterwards. In most cases these patients were excluded from the target population. Of the remaining 6864 patients, 3016 patients were not given a card with an instruction to use the computer because the emergency nurses felt they would not be able to complete the computerized questionnaire for the reasons noted above. Another 1508 patients (39\%) were lost because the triage nurses forgot to give the patients the card, often because too many patients were presenting within a short time period. An additional $278(7 \%)$ patients were given the card but chose not to participate. Thus, of the patients initially admitted to triage, 2062 patients (54\%) answered the computerized questionnaire. Of these, 1356 patients were categorized as non-injury patients and excluded from this study. Of the 706 injury patients, the 140 who were categorized as abstainers were also excluded from the study, resulting in a study population of 566 injured patients.

\section{Measures}

Acute alcohol consumption was defined as self-reported consumption of alcohol in the 6 hours preceding the injury, a common definition used in international ED studies. Sociodemographic data included gender, age, education, and occupation. Data concerning three drinking variables were obtained from the computer program: frequency of drinking, typical quantity of drinking, and frequency of heavy episodic drinking (HED).

Frequency of drinking was measured as follows: every day; almost every day; $3-4$ times per week; 1-2 times per week; 2-3 times per month; about once a month; less often than monthly; had not been drinking during the past year. Typical quantity of drinking was measured as follows: 1 standard glass; 2-3 standard glasses; 4-5 standard glasses; 6-7 standard glasses; 8-9 standard glasses; 10 standard glasses or more. One standard drink equals $12 \mathrm{~g}$ of pure alcohol.

Responses regarding frequency of drinking and typical quantity were combined to calculate weekly consumption for each patient, according to a method suggested by Seppä, et al., (1995), whereby, for example, drinking 1-2 times per week is counted as 2 times per week and a typical quantity of 4-5 standard glasses is counted as drinking 5 standard glasses, yielding a weekly consumption of 10 standard glasses for this individual.

HED was defined as consuming 4 drinks or more on one occasion for women and 5 drinks or more on one occasion for men. This standard is widely applied in the international alcohol literature (Dawson, et al., 2005; Reinert \& Allen, 2007). Frequency of HED was categorized as follows: never; less than monthly; about once per month; 2-3 times per month; 1-2 times per week; 3-4 times per week; almost every day or every day. To estimate the number of HED occasions per month, the same principle of using the highest amount in an interval was applied. 
Risky drinking was defined as consuming 10 or more drinks weekly for women ( $\geq 120 \mathrm{~g}$ ) and 15 or more ( $\geq 180 \mathrm{~g}$ ) for men, or engaged in HED (as defined above) once a month or more often. This composite risk drinking definition has been promoted in Sweden by the National Public Health Institute and The National Board of Health and Welfare (Socialstyrelsen, 2007).

The connection between the injury and alcohol was assessed by asking the patients whether they believed that there was a connection between the injury and their drinking. Two response categories were constructed: "connection to injury" ("yes, definitely" "yes, likely" and "possibly") and "no connection" ("had not been drinking" and "no connection"). This question has been validated and is commonly used in ED studies (Cherpitel et al., 2006).

Patients' motivation to reduce drinking was assessed by asking patients (excluding abstainers) to select, from four options, the response that best described their current attitude toward reducing their alcohol consumption. The response options were translated to Swedish and labeled in accordance with Prochaska and DiClemente's Stages of Change Theory, as suggested by Prochaska, et al., (1992), and operationalized by Leontieva et al. (2005): pre-contemplation ("I have no thoughts of reducing"); contemplation ("I need to consider reducing someday"); preparation ("I'm thinking about how to reduce my drinking"); and action ("I'm cutting down on my drinking"). The Stages of Change Theory posits that individual's progress through distinct stages of motivation to change and that interventions need to be matched to individuals' current stage of motivation (Prochaska et al., 1992).

All the injury patients were asked if their injury had made them more motivated to reduce their alcohol consumption. The response items were: "my motivation to reduce my drinking was affected to a large extent by the injury"; "my motivation to reduce my drinking was affected to some extent by the injury"; and "my motivation to reduce my drinking was not affected by the injury". Two categories were constructed: "yes" (combining the two response items that made an association) and "no" (the response item that did not make an association).

Physical distress was assessed by asking the patient if their injury caused them physical distress or pain. The response items were "none", "minor", "moderate" and "severe". Two response categories were constructed: "yes" ("minor", "moderate" and "severe") and "none" ("none"). Similarly, mental distress was assessed by asking the patient if their injury caused them mental distress. The response items were "none", "minor", "moderate" and "severe". In this study two response categories were constructed: "yes" ("minor", "moderate" and "severe") and "none" ("none").

\section{Analysis}

Pearson's $\chi^{2}$-test and Fisher's exact test, when appropriate, were used to analyze the differences in distribution regarding sociodemographic characteristics and proportion of risky drinkers. Differences in average weekly consumption were tested using the $t$-test. Differences concerning frequency of HED occasions per month were tested with nonparametric tests, the Kruskal-Wallis test and the Mann-Whitney test. Statistical significance was set at $p<0.05$. PASW Statistics 18 statistical software was used for all analyses.

\section{Results}

Of the 566 injured patients, 85 (15\%) were categorized as acute drinkers and of these, $64 \%$ reported that their injury was connected with their alcohol consumption (results not shown). 
Acute and non-acute drinkers were significantly different on all sociodemographic and drinking characteristics examined, except for gender (Table 1). Acute drinkers were in general younger $(p<0.001)$ than non-acute drinkers. Three-quarters $(75 \%)$ of the acute drinkers were men compared to $67 \%$ of the non-acute drinkers $(p<0.001)$. Acute drinkers were also categorized as risky drinkers to a much greater extent $(p<0.001)$ than non-acute drinkers, and reporting a considerably higher average weekly alcohol consumption (186 g/ week vs $54 \mathrm{~g} /$ week; $p<0.001)$ and engaging far more frequently in HED (6.6 events/week vs 1.9 events/week; $p<0.001)$.

There were also statistically significant differences between acute drinkers and non-acute drinkers concerning motivation to reduce drinking $(p<0.001)$ (Table 2). Acute drinkers were motivated to a greater extent than non-acute drinkers to reduce their alcohol intake; 51\% were at the action, preparation, or contemplation stages, compared with $19 \%$ of the nonacute drinkers $(p<0.001)$. Acute drinkers stated that the injury had led to increased motivation to reduce their drinking to a far higher degree than the non-acute drinkers ( $27 \%$ vs $2 \% ; p<0.001)$. However, the extent to which the injury caused physical and mental distress did not differ significantly between the acute and non-acute drinkers.

\section{Discussion}

This study investigated the prevalence of acute alcohol consumption among injury patients in a Swedish ED and their sociodemographic and drinking characteristics. We also examined the importance of factors associated with motivation to reduce alcohol consumption among these patients. Approximately one in seven injury patients in this study had been drinking in the 6 hours preceding the event that led to the injury (i.e., were acute drinkers), which is similar to earlier Swedish studies on non-fatal injuries (Nilsen et al., 2007b; Nordqvist et al., 2006; Romelsjö et al., 1993), but lower than most of the ED studies included in the international Emergency Room Collaborative Alcohol Analysis Project (ERCAAP) and WHO Collaborative Study on Alcohol and Injuries (Cherpitel et al., 2003; World Health Organization, 2007). Only five of these 28 studies, from 16 countries, reported a similar or lower proportion of acute drinkers, and the 2001 study from Malmö, Sweden reported $15 \%$ excluding abstainers; the same proportion found here.

The acute drinkers demonstrated more detrimental drinking patterns than non-acute drinkers, i.e., drinking a considerably higher weekly quantity and engaging in HED more often. Risk drinking was more prevalent among the acute drinkers; $80 \%$ of the acute drinkers were categorized as risk drinkers compared with $42 \%$ of the non-acute drinkers. The overall proportion of risk drinkers seen in our study was very high, with $47 \%$ of the injury patients being categorized as risk drinkers on the basis of the accepted Swedish definition of risk drinking. Thirty-one percent of the Swedish general population were categorized as risk drinkers in a recent study (Nilsen, et al., 2011) using the same definition as in our study. Hence, it is obvious that the proportion of risk drinkers is considerably higher in our ED population of injury patients than in the general Swedish population.

Our study population was very young, with more than half of the patients below 40 years of age, and two-thirds were male. These age and gender characteristics are largely consistent with the overall epidemiology of non-fatal injuries in developed countries; the injury rate for males is twice the rate for females and the age categories accounting for the largest number of injuries are toddlers (1-4 years old), teenagers, young adults, and the elderly (Barss, et al., 1998). Hence, to a large extent, the demographic characteristics of those with the highest alcohol consumption, i.e., an over-representation of young males, correspond to those at greatest risk of injury. 
The acute and non-acute drinkers differed greatly in their motivation to change their drinking, according to the Stages of Change Theory. Approximately half of the acute drinkers stated that they were content with their current drinking level, compared with fourfifths of the non-acute drinkers. The acute and non-acute drinkers differed considerably on the effect of the injury on their motivation to reduce their drinking, with only $2 \%$ of the nonacute drinkers believing that the injury had had an effect on their motivation compared with more than one-fourth of the acute drinkers. This was expected in view of the research that suggests injured patients with high alcohol consumption are particularly motivated to change their drinking behavior if they perceive a connection between their drinking and the injury (Longabaugh et al., 1995). It has been suggested that an injury provides a teachable moment in which the aversive experience naturally produces a period when the individual is contemplating behavior change (Gentilello et al., 1999).

\section{Limitations}

This study involves a number of limitations that must be considered when interpreting the results. In this study, self-reporting was used to measure alcohol intake. Alcohol selfreporting measures tend to be valid and reliable under most circumstances (Babor \& Kadden, 2005). Studies have found self reports of drinking prior to injury to be highly valid when compared to breathalyzer readings on ED admission (Cherpitel, 1989; Cherpitel 1992; Cherpitel 1993; Cherpitel et al., 2007) and ED patients are more likely to provide accurate reports of alcohol habits if they feel that the disclosure could be important in their emergency care. However, research suggests that self-reporting validity may be even higher when the alcohol consumption information is less closely related to the injury event, e.g., when patients are asked about overall drinking patterns, as was done in the present study, because these more general questions do not necessarily imply a causal association between alcohol and the event (Cherpitel, 1999). Obviously, some underreporting cannot be ruled out. However, it is very difficult to determine the extent of underreporting and whether a study set in Sweden produces greater underreporting than studies conducted elsewhere.

Some of the differences between our findings and those of other studies could be attributed to differences in methodology. We used computer technology to obtain epidemiologic data on ED patients. The use of computers has been found to decrease the effect of social desirability and increase the amount of information disclosed (Robinson \& West, 1992; Tate, et al., 2001; Thomas, et al., 1997). Findings suggest that patients prefer to reveal information of a personal and potentially embarrassing nature to a computer than a person (Locke et al., 1999; Tourangeau \& Smith, 1996). Thus, patients in our study may have felt more comfortable reporting that they consumed large amounts of alcohol because of the increased anonymity in a computerized questionnaire.

External drop-out was considerable because $37 \%$ of the target population was not given a card due to oversight by the triage staff. This loss of patients may have biased the results, but it is difficult to speculate how the drinking patterns of these patients may have differed from those included in the study. It is possible that these omissions more often occurred when the ED triage room was undermanned, e.g., during the night, when a high proportion of patients with alcohol-related injury may have been admitted. If this was the case, a number of patients with more detrimental drinking patterns might have been excluded from the study population, thus underestimating the prevalence of high risk drinking in this population. Internal drop-out was fairly sizeable for some of the drinking questions. Although the drop-out analysis revealed no difference in the response rate between women and men, internal drop-out was more common among the older age categories (50-69 years), who typically drink less and engage in HED less frequently than those 49 years and younger. This suggests that internal drop-out could have biased the results towards more detrimental drinking patterns in the population. 
The refusal rate in this study was only $7 \%$, which compares favorably with many ED intervention studies in which attrition due to patient refusal typically ranges between $15 \%$ and 35\% (Conigrave, et al., 1991; Crawford et al., 2004; Forsberg, et al., 2000; Johnston, et al, 2002; Maio et al., 2000; Neumann et al., 2006; Watson, 1999). Some confusion on the part of the patients regarding drink size may have arisen. For example, a person consuming a bottle of wine prior to injury may overestimate the number of drinks in a bottle. During a face-to-face interview, the interviewer converts such reports to standard drinks.

\section{Conclusion}

We found that $15 \%$ of the injured patients (excluding abstainers) were acute drinkers (i.e., had drunk alcohol $6 \mathrm{~h}$ prior to the injury). Of these, two-thirds acknowledged a connection between their injury and their alcohol consumption. Acute drinkers had considerably more detrimental alcohol consumption (i.e., drinking a higher weekly volume and more often engaging in HED) than those who did not drink 6 hours prior to the injury. The overall proportion of risk drinkers was very high; $47 \%$ of the injury patients were categorized as risk drinkers on the basis of their weekly intake or frequency of HED, in accordance with the accepted Swedish definition of risk drinking. However, the acute drinkers were more motivated to reduce their drinking than the non-acute drinkers.

\section{References}

Allely P, Graham W, McDonnell M, Spedding R. Alcohol levels in the emergency department: a worrying trend. Emergency Medicine Journal. 2006; 23:707-708. [PubMed: 16921087]

Babor TF, Kadden RM. Screening and interventions for alcohol and drug problems in medical settings: what works? Journal of Trauma. 2005; 59:80-87. discussion 94-100. [PubMed: 16096543]

Barss, P.; Smith, G.; Baker, S.; Mohan, D. Injury prevention: an international perspective. New York: Oxford University Press; 1998.

Bombardier CH, Ehde D, Kilmer J. Readiness to change alcohol drinking habits after traumatic brain injury. Archives of Physical Medicine and Rehabilitation. 1997; 78:592-596. [PubMed: 9196466]

Bombardier CH, Rimmele CT. Alcohol use and readiness to change after spinal cord injury. Archives of Physical Medicine and Rehabilitation. 1998; 79:1110-1115. [PubMed: 9749693]

Cherpitel CJ. Breath Analysis and Self-Reports as Measures of Alcohol-Related Emergency Room Admissions. Journal of Studies on Alcohol. 1989; 50:155-161. [PubMed: 2927129]

Cherpitel CJ, Parés A, Rodés J, Rosovsky H. Validity of Self-reported Alcohol Consumption in the Emergency Room: Data from the U.S. Mexico, and Spain. Journal of Studies on Alcohol. 1992; 53:203-207. [PubMed: 1583899]

Cherpitel CJ. Timing in breathe analyzer: does it make a difference? Journal of Studies on Alcohol. 1993; 54:517-519. [PubMed: 8412139]

Cherpitel CJ. Emergency room and primary care services utilization and associated alcohol and drug use in the United States general population. Alcohol and Alcoholism. 1999; 34:581-589. [PubMed: 10456587]

Cherpitel CJ. Alcohol and injuries: a review of international emergency room studies since 1995. Drug and Alcohol Review. 2007; 26:201-214. [PubMed: 17364856]

Cherpitel CJ, Bond J, Ye Y, Borges G, Macdonald S, Giesbrecht N. A cross-national meta-analysis of alcohol and injury: data from the Emergency Room Collaborative Alcohol Analysis Project (ERCAAP). Addiction. 2003; 98:1277-1286. [PubMed: 12930215]

Cherpitel CJ, Bond J, Ye Y, Rehm J, Borges G, Room R, et al. Multi-level analysis of causal attribution of injury to alcohol: data from two international emergency room projects. Drug and Alcohol Dependence. 2006; 82:258-268. [PubMed: 16257137]

Cherpitel CJ, Ye Y, Bond J, Borges G, Macdonald S, Stockwell T, Room R, Sovinova H, Marais S, Giesbrecht N. Validity of self-reported drinking before injury compared with a physiological measure: Cross-national analysis of emergency department data form 16 countries. Journal of Studies on Alcohol. 2007; 68:296-302. 
Conigrave KM, Burns FH, Reznik RB, Saunders JB. Problem drinking in emergency department patients: the scope for early intervention. Medical Journal of Australia. 1991; 154:801. [PubMed: 2041505]

Crawford MJ, Patton R, Touquet R, Drummond C, Byford S, Barrett B, et al. Screening and referral for brief intervention of alcohol-misusing patients in an emergency department: a pragmatic randomised controlled trial. Lancet. 2004; 364:1334-1339. [PubMed: 15474136]

Dawson D, Grant B, Stinson F, Zhou Y. Effectiveness of the derived Alcohol Use Disorders Identification Test (AUDIT-C) in screening for alcohol use disorders and risk drinking in the US general population. Alcoholism: Clinical and Experimental Research. 2005; 29:844-854.

Deutch SR, Hoyer CCS, Christensen EF, Dragsholt C, Hansen AC, Kristensen IB, et al. Drug and alcohol use among patients admitted to a Danish trauma centre: a prospective study from a regional trauma centre in Scandinavia. European Journal of Emergency Medicine. 2004; 11:318322. [PubMed: 15542988]

Forsberg L, Ekman S, Halldin J, Rönnberg S. Brief interventions for risk consumption of alcohol at an emergency surgical ward. Addictive Behaviors. 2000; 25:471-475. [PubMed: 10890304]

Gentilello LM, Rivara FP, Donovan DM, Jurkovich GJ, Daranciang E, Dunn CW, et al. Alcohol interventions in a trauma center as a means of reducing the risk of injury recurrence. Annals of Surgery. 230:473-480. [PubMed: 10522717]

Johnston BD, Rivara FP, Droesch RAM, Dunn C, Copass MK. Behaviour change counseling in the emergency department to reduce injury risk: a randomized, controlled trial. Pediatrics. 2002; 110:267-274. [PubMed: 12165577]

Kuendig H, Hasselberg M, Gmel G, Daeppen JB, Laflamme L. Acute and usual drinking among emergency trauma patients: a study on alcohol consumption and injury patterns. Injury Prevention. 2009; 15:270-274. [PubMed: 19652002]

Kuendig H, Hasselberg M, Laflamme L, Daeppen JB, Gmel G. Acute alcohol consumption and injury: risk associations and attributable fractions for different injury mechanisms. Journal of Studies on Alcohol and Drugs. 2008; 69:218-226. [PubMed: 18299762]

Leontieva L, Horn K, Haque A, Helmkamp J, Ehrlich P, Williams J. Readiness to change problematic drinking assessed in the emergency department as a predictor of change. Journal of Critical Care. 2005; 20:251-256. [PubMed: 16253794]

Locke SE, Kowaloff HB, Hoff RG, Safran C, Popovsky MA, Cotton DJ, et al. Computer-based interview for screening blood donors for risk of HIV transmission. JAMA. 1999; 268:1301-1305. [PubMed: 1507376]

Longabaugh R, Minugh PA, Nirenberg TD, Clifford PR, Becker B, Woolard R. Injury as a motivator to reduce drinking. Academic Emergency Medicine. 1995; 2:817-825. [PubMed: 7584769]

Maio RF, Shope JT, Blow FC, Copeland LA, Gregor MA, Brockmann LM, et al. Adolescent injury in the emergency department: opportunity for alcohol. Annals of Emergency Medicine. 35:252-257. [PubMed: 10692192]

Myndigheten för Samhällsskydd och Beredskap (MSB). Karlstad, Sweden: 2010. https://www.msb.se/

Neumann T, Neuner B, Weiss-Gerlach E, Tonnesen H, Gentilello LM, Wernecke KD, et al. The effect of computerized tailored brief advice on at-risk drinking in subcritically injured trauma patients. Journal of Trauma. 2006; 61:805-814. [PubMed: 17033544]

Nilsen P, Holmqvist M, Nordqvist C, Bendtsen P. Frequency of heavy episodic drinking among nonfatal injury patients attending an emergency room. Accident Analysis and Prevention. 2007a; 39:757-766. [PubMed: 17217905]

Nilsen P, Holmqvist M, Nordqvist C, Bendtsen P. Linking drinking to injury - causal attribution of injury to alcohol intake among patients in a Swedish emergency room. International Journal of Injury Control and Safety Promotion. 2007b; 14:93-102. [PubMed: 17510845]

Nilsen P, McCambridge J, Karlsson N, Bendtsen P. Brief intervention in routine health care: a population-based study of conversations about alcohol in Sweden. Addiction. 201110.1111/j. 1360-0443.2011.03476.x

Nordqvist C, Holmqvist M, Nilsen P, Bendtsen P, Lindqvist K. Usual drinking patterns and non-fatal injury among patients seeking emergency care. Public Health. 2006; 120:1064-1073. [PubMed: 17007896] 
Prochaska JO, DiClemente CC, Norcross JC. In search of how people change. American Psychologist. 1992; 47:1102-1114. [PubMed: 1329589]

Reinert DF, Allen JP. The Alcohol Use Disorders Identification Test: an update of research findings. Alcoholism: Clinical and Experimental Research. 2007; 31:185-199.

Robinson R, West R. A comparison of computer and questionnaire methods of history-taking in a genito-urinary clinic. Psychology and Health. 1992; 6:77-84.

Romelsjö A, Alberts K, Andersson R. The Stockholm County programmes for accident and alcohol prevention and injury surveillance - initial experiences. Addiction. 1993; 88:1013-1016. [PubMed: 8358255]

Seppä K, Mäkelä R, Sillanaukee P. Effectiveness of the Alcohol Use Disorder Identification Test in occupational health screenings. Alcoholism: Clinical and Experimental Research. 1995; 19:999_ 1003.

Socialstyrelsen (The National Board of Health and Welfare). Nationella riktlinjer för Missbruks- och Beroendevård. 2007

Tate DF, Wing RR, Winett RA. Using Internet technology to deliver a behavioral weight loss program. JAMA. 2001; 285:1172-1177. [PubMed: 11231746]

Thomas R, Cahill J, Santilli L. Using an interactive computer game to increase skill and self-efficacy regarding safer sex negotiation: field test results. Health Education \& Behavior. 1997; 24:71-86. [PubMed: 9112099]

Tourangeau R, Smith TW. Asking sensitive questions. The impact of data collection mode, question format, and question context. Public Opinion Quarterly. 1996; 60:275-304.

Vitale SG, van de Mheen D, Garretsen HFL, van de Wiel A. Self-reported alcohol use among Dutch emergency room patients: variations in prevalence rates owing to methodological differences. Alcohol and Alcoholism. 2005; 40:524-530. [PubMed: 16087657]

Watson HE. Problem drinkers in acute care settings: validation of an assessment instrument. International Journal of Nursing Studies. 1999; 36:415-423. [PubMed: 10519686]

World Health Organization. Alcohol and injury in emergency departments: summary of the report from the WHO collaborative study on alcohol and injuries. Geneva: World Health Organization; 2007. 


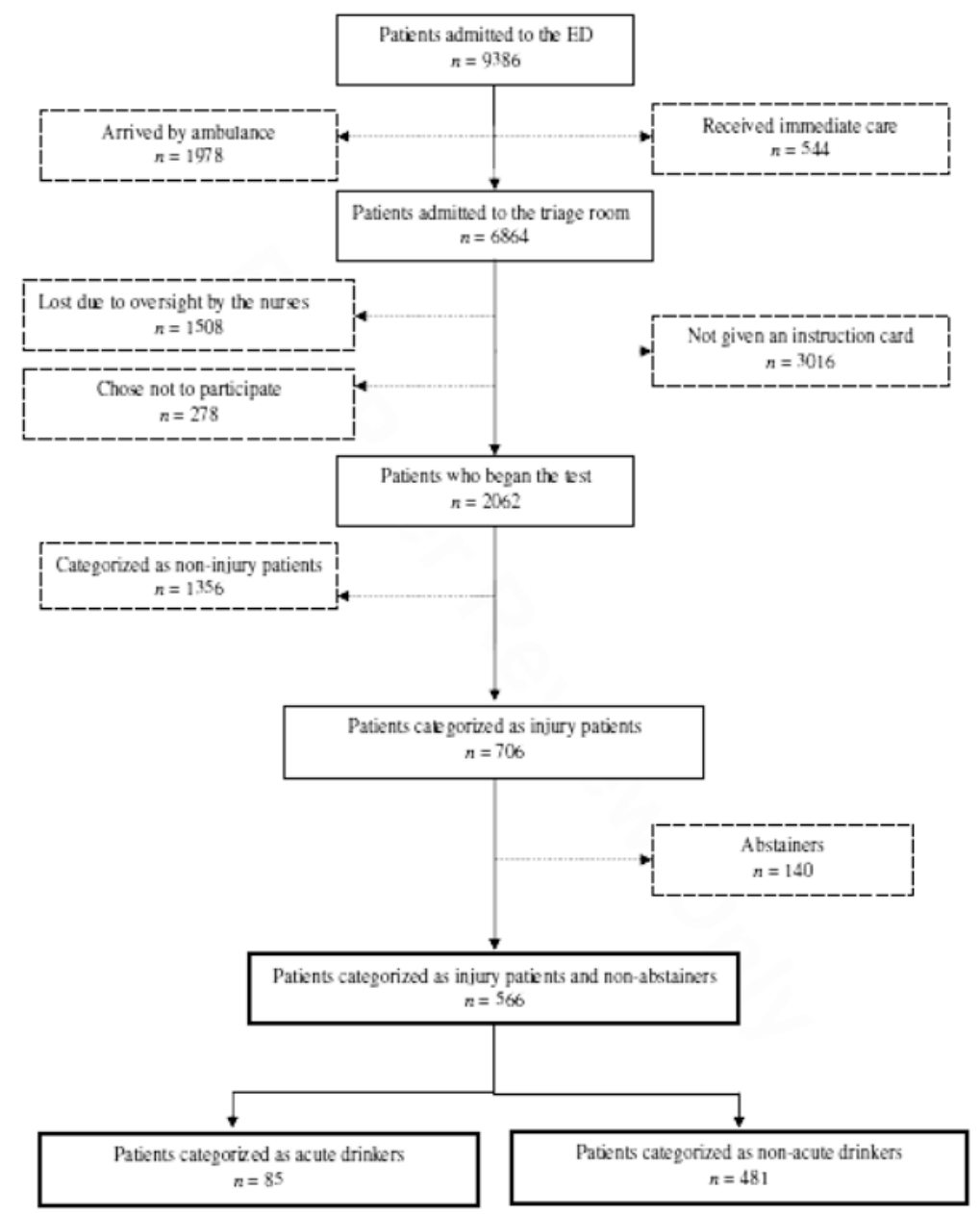

Figure 1.

Flow chart. 